\title{
Opportunities to Improve the Role of Family Practice Nurses in Increasing the Uptake of Evidence-Based Smoking Cessation Interventions for Pregnant Women: An Exploratory Survey
}

\author{
Christina Cantin ${ }^{* 1}$, Wendy E. Peterson ${ }^{2}$, Barbara Davies ${ }^{2}$ and Kirsten Woodend ${ }^{3}$ \\ ${ }^{1}$ Champlain Maternal Newborn Regional Program, Ottawa, Canada \\ ${ }^{2}$ School of Nursing, Faculty of Health Sciences, University of Ottawa, Ottawa, Canada \\ ${ }^{3}$ Trent-Fleming School of Nursing, Peterborough, Canada
}

*Corresponding author: Christina Cantin, Perinatal Consultant, Champlain Maternal Newborn Regional Program, 2305 St Laurent Blvd, Ottawa, ON K1G4J8, Canada, Tel: 1613-737-2660; E-mail: ccantin@cmnrp.ca

Rec date: March 18, 2014; Acc date: October 25, 2014; Pub date: December15, 2014

Copyright: (c 2014 Cantin C, et al. This is an open-access article distributed under the terms of the Creative Commons Attribution License, which permits unrestricted use, distribution, and reproduction in any medium, provided the original author and source are credited.

\begin{abstract}
Background: Approximately $6-30 \%$ of Canadian women smoke during pregnancy. Prenatal care visits are an opportune time for Family Practice Nurses to provide evidence-based smoking cessation interventions. The purpose of this exploratory study was to describe: 1) Smoking cessation interventions by Family Practice Nurses during prenatal visits; 2) Family Practice Nurses' awareness and use of smoking cessation guidelines as well as the proportion of Family Practice Nurses who engage pregnant women who smoke in minimal interventions and intensive interventions; 3 ) the predictors of nurse-provided smoking cessation counseling for pregnant women and 4) the barriers to smoking cessation counseling.
\end{abstract}

Methods: A previously validated questionnaire measuring smoking cessation counseling practices was modified and converted to an electronic format. A bilingual invitation was emailed to the members of Ontario Family Practice Nurses' interest group of the Registered Nurses' Association of Ontario, Canada. Descriptive and multivariate analyses were completed. Predictors investigated included nurses' age, beliefs about their role in smoking cessation, self-efficacy to provide effective counseling, smoking cessation training, and interest in updating smoking cessation knowledge. Eighty-nine Family Practice Nurses working in primary care settings across Ontario, Canada responded.

Results: Nurses with higher levels of self-efficacy were more likely to provide smoking cessation counseling. Although nurses Ask, Advise and Assess, they are less likely to provide concrete assistance in the quitting process or arrange follow-up. The most commonly cited barriers to nurse-provided smoking cessation counseling included cost of medication, lack of time, and lack of knowledge. Fourteen percent of respondents reported that they never offer smoking cessation counseling to pregnant women.

Conclusions: Family Practice Nurses are not consistently providing evidence-based smoking cessation interventions for pregnant women. Disseminating research outlining effective strategies to increase nurses' selfefficacy to provide effective smoking cessation interventions may increase the uptake of evidence-based recommendations.

Keywords: Smoking cessation; Pregnancy; Primary care; Family Practice Nurses; Prenatal care; Evidence-based guidelines; Health promotion

\section{Introduction}

Smoking cessation (SC) counseling for pregnant women continues to warrant concerted diligence by health care professionals. The prevalence rates of smoking during pregnancy range from $6-34 \%$ in Canada, the United States and Australia [1-5]. The wide range in prevalence rates is likely due to the associated negative social stigma; mothers are reluctant to disclose their smoking behaviours due to feelings of guilt and shame [6-8]. However, there is no safe amount of smoking during pregnancy. Consequently perinatal health care providers, including nurses, must actively support women's efforts to stop smoking $[7,9,10]$.
The 5 A's (Ask, Advise, Assess, Assist \& Arrange) approach to treating tobacco use and dependence is the most frequently cited evidence-based strategy pertaining to SC counselling interventions [11]. Additionally, there are best practice guidelines that have been developed to specifically acknowledge the important role of nurses in SC [12]. Many guidelines include sections addressing special considerations for specific populations such as pregnant women $[7$, $13]$.

The prenatal period is an opportune time to provide ongoing support and interventions for SC counselling due to the frequency of health care visits and women's high motivation to quit $[14,15]$. Every opportunity should be taken to assist women and their partners to reduce fetal and infant exposure to the harmful effects of tobacco smoking [16]. Given that $62 \%$ of women who quit smoking during pregnancy relapse within one year [3], counselling and support should 
Citation: Cantin C, Peterson WE, Davies B, Woodend K (2014) Opportunities to Improve the Role of Family Practice Nurses in Increasing the Uptake of Evidence-Based Smoking Cessation Interventions for Pregnant Women: An Exploratory Survey. Primary Health Care 4: 174. doi:10.4172/2167-1079.1000174

Page 2 of 8

be provided throughout the perinatal period and continue beyond the pregnancy.

Despite the availability of evidence-based guidelines, there is variable uptake by nurses, midwives, and physicians in implementing practice recommendations [17-20]. Specifically, these studies have identified conflicting advice, inconsistent application of smoking cessation interventions, and lack of follow-up, as common problems. In Ontario, Canada, Family Practice Nurses (FPNs) work in primary care settings in collaboration with family physicians, and nurse practitioners. FPNs care for a range of patient populations including pregnant women. FPNs typically see women early and throughout pregnancy, postpartum and families' childbearing years. FPNs are therefore well positioned to provide early SC interventions and ongoing support. For example, postpartum interventions include encouraging smoke-free homes and teaching harm reduction strategies that can minimize infants' exposure to smoke $[12,13]$. Our search of the literature reveals a dearth of studies in which the role of FPNs, in providing smoking cessation interventions for pregnant women, has been examined. The purpose of this study was to explore the role of Family Practice Nurses (FPNs), in smoking cessation counselling for pregnant women.

\section{Specific research questions include}

1. What are 'Family Practice Nurses' current smoking cessation counselling practices for pregnant women seeking care at primary care settings in Ontario during routine visits?

2. What is FPNs' awareness and use of guidelines pertaining to smoking cessation? What proportion of FPNs engage pregnant smokers in minimal interventions and intensive interventions?

3. What factors are associated with Family Practice Nurses' smoking cessation counselling practices for pregnant women?

4. What are the barriers to FPN-led smoking cessation counselling interventions of pregnant smokers?

\section{Methods}

The study design was non-experimental, descriptive and correlational. The setting was primary care practices in the province of Ontario, Canada. A one-time cross-sectional electronic questionnaire was administered to a convenience sample of FPNs who provide prenatal care in primary care settings. In Ontario there are seven major models of primary care services that provide government funded health care such as Family Health Teams, Community Health Centres, and Family Health Networks [21,22]. There are approximately 4,300 primary care nurses in Ontario [22]. Participants were recruited via the Ontario Family Practice Nurses' Interest Group of the Registered Nurses' Association of Ontario (RNAO). The RNAO is a voluntary professional association for nurses. The inclusion criteria were: 1) currently employed as a nurse at a primary care setting in Ontario; 2) provide direct care for prenatal patients; and 3) able to read and write in English.

The data collection instrument for this study was a questionnaire modified from the "Smoking cessation counselling practices among Quebec nurses" questionnaire [19]. Utilizing the questionnaire by Tremblay et al. had two major benefits. First, the questionnaire had been previously administered to nurses [23]. Second, this instrument has been demonstrated to be reliable [19].

To collect data exclusively on the current smoking cessation interventions of Family Practice Nurses for pregnant women, four steps were taken to modify the questionnaire: conduct a literature review, obtain feedback on the questionnaire from four experts in perinatal care and/or smoking cessation, convert the final version of the questionnaire to electronic format in Survey Monkey and pre-test the modified questionnaire with five graduate students in the Masters in Nursing program at a large urban university who had experience in either smoking cessation counselling/interventions, primary health care or perinatal nursing.

\section{Variables}

\section{Cessation counselling}

In order to provide interventions and support to pregnant women who smoke, it is recommended that FPNs initially determine women's readiness to quit and motivation to quit [6]. Pregnant women will be either ready to quit or they will not be ready to quit and the subsequent interventions would necessarily be different. In this study, therefore, both of these situations were explored by utilizing two independent scales from the work of Tremblay et al. [19]: A "ready to quit" counselling scale and a "not ready to quit" counselling scale. Response options for each item in the scales ranged from 1 (FPN undertook practice with few or none of her pregnant patients who smoked) to 5 (FPN undertook practice with all or almost all of her pregnant patients who smoked).

\section{"Ready to quit" counselling scale}

The "ready to quit" counselling scale score quantifies FPNs' smoking cessation counselling practice with pregnant women who have indicated readiness to quit. This scale is comprised of 10 fivepoint likert scale items (minimum score $=10$; maximum=50) with higher total scores indicating FPNs provided more SC counselling to pregnant women who were "ready to quit" smoking.

\section{"Not ready to quit" counselling scale}

The "not ready to quit" counselling scale score quantifies FPNs' smoking cessation counselling practice with pregnant women who have indicated that they are not ready to quit. This scale is comprised of nine five-point likert scale items to determine the total "not ready to quit" counselling scale score (minimum score $=9$; maximum $=45$ ) with higher scores indicating FPNs provided more SC counselling to pregnant women who were "not ready to quit" smoking.

\section{Awareness and Use of Guidelines}

Respondents were asked about their awareness and use of SC guidelines at their place of work. Given that the respondents were members of the Ontario Family Practice Nurses' interest group of the Registered Nurses' Association of Ontario (RNAO), it was hypothesized that they would be aware of the RNAO best practice guideline (BPG) entitled "Integrating Smoking Cessation into Daily Nursing Practice" [12]. This BPG includes recommendations for nursing practice that are applicable to nurses working in all settings, with all patient populations and is available free on the internet. Respondents were asked about their practice related to two specific practice recommendations pertaining to minimal and intensive intervention. The first practice recommendation from the RNAO BPG suggests that "nurse's implement minimal tobacco use intervention using the "Ask, Advise, Assist, Arrange" protocol with all clients" (p. 22) [12]. Minimal intervention is defined as lasting one to three 
Citation: Cantin C, Peterson WE, Davies B, Woodend K (2014) Opportunities to Improve the Role of Family Practice Nurses in Increasing the Uptake of Evidence-Based Smoking Cessation Interventions for Pregnant Women: An Exploratory Survey. Primary Health Care 4: 174. doi:10.4172/2167-1079.1000174

Page 3 of 8

minutes. Practice recommendation number six suggests that "nurses implement, wherever possible, intensive intervention with women who are pregnant and postpartum" (p.29) [12]. Intensive intervention is defined as lasting more than 10 minutes. Respondents were asked to estimate the amount of time that they spend providing smoking cessation counselling during a prenatal visit. Response options included: more than 10 minutes, 6-10 minutes, 3-5 minutes, less than 3 minutes, and "I never offer smoking cessation counselling".

\section{Factors that influence counselling practices}

Six independent variables were examined to determine if they were significant predictors of FPNs' SC counselling of pregnant women who were either "ready to quit" or "not ready to quit". The variables were FPNs' beliefs (defined as the belief that cessation counselling is the role of nurses), self-efficacy (defined as the self-perceived ability to provide effective cessation counselling), age, interest in updating smoking cessation knowledge, smoking cessation training received during nursing studies, and smoking cessation training received after nursing studies.

The variables were measured by either multi-item scales or single item indicators. Two multi-item scales were developed to analyse the variables "beliefs" and "self-efficacy" [19]. The variable "beliefs" was measured as the sum of six items related to beliefs $(\alpha=.76)$. The variable "self-efficacy" was measured as the sum of 5 items $(\alpha=.89)$. These scales were then verified to ensure that the Cronbachs Alpha were $\geq 0.7$ [24] and that the reliability scores were consistent with those reported by Tremblay et al for beliefs $(\alpha=.76)$ and self-efficacy $(\alpha=.84)$ [19]. The remaining four independent variables were measured as single item indicators. Respondents were asked to indicate the year in which they were born and to reply yes/no to questions about their training and interest in smoking cessation.

\section{Barriers}

In order to better understand the reasons why FPNs may not offer SC counselling, the respondents were asked to identify the extent to which 17 factors were perceived to be barriers to providing SC interventions for pregnant women. Response categories were the following: highly significant barrier, significant barrier, sometimes a barrier, rarely a barrier, and never a barrier.

\section{Data Collection}

Ethical approval was obtained from the University of Ottawa Office of Research Ethics and Integrity. The Ontario Family Practice Nurses' interest group of RNAO sent an e-mail invitation in English \& French via the group distribution list which included 503 member e-mail addresses. Data were collected between October 2011 and December 2011. The tailored design method was used to recruit participants [25]. A total of four contacts were sent (one e-mail invitation and three reminder e-mails), with all e-mail messages including a hyperlink to the SurveyMonkey questionnaire. A record documenting tracking of the e-mail messages was maintained.

\section{Data Analysis}

The questionnaire data was downloaded from the SurveyMonkey website and imported into Statistical Package for the Social Sciences
(SPSS) version 19.0. Respondents were excluded from data analysis if they did not complete the demographics section at the end of the questionnaire.

Descriptive statistics were compiled to describe the characteristics of the participants. To limit the number of variables used in a multiple linear regression, separate simple linear regressions were completed for the dependent variables "ready to quit" and "not ready to quit" with the six independent variables. Independent variables that had a significance level of $\mathrm{p}<.20$ were entered into a multiple linear regression analysis [24].

\section{Results}

It was noted by the Ontario Family Practice Nurses' Interest Group that $3 \%(n=13)$ of messages were not delivered. One hundred FPNs entered the SurveyMonkey link. Of these $100 \mathrm{FPNs}$, four identified that they did not wish to participate, and seven said yes to participation in the study but did not answer any of the questions. Therefore, the response rate for this study was $18 \%(n=89)$. A further 25 respondents did not complete the demographics section of the questionnaire and were excluded from the data analysis resulting in a sample size of 64 .

\section{Demographics of FPNs}

FPNs' demographics, smoking status and smoking cessation training are summarized in Table 1 . All respondents were female. The majority of respondents were employed as registered nurses (91\%) at either a Family Health Team (44\%) or a physician's office $(40 \%)$. There was nearly equal distribution of respondents from each of the sizes of communities in which the respondents worked, with somewhat more respondents in the rural group (33\%). Two-thirds of the respondents worked full time (64\%) and two-thirds reported that they were in their current position for less than 5 years (58\%).

The FPNs' mean age was 48, with ages ranging from 26-67 years. The majority of respondents had a diploma in nursing (70\%) which is obtained by completing a two or three year college program, while the remainder had a four year university degree in nursing. A small number of respondents received SC training during their studies (13\%) and there was a threefold increase in the number of nurses who received SC training after their nursing studies (39\%). Two-thirds of the FPNs reported always being non-smokers (64\%) while one-third reported being ex-smokers (34\%). There were no daily smokers and only one occasional smoker.

Current Smoking Cessation Counselling Practices with Pregnant Women

The majority of respondents (70\%) reported that they see one to five pregnant women per day, with a further $12 \%$ of respondents who see more than five pregnant women per day. Respondents were asked to estimate the proportion of pregnant women who smoke for whom they routinely completed any of the the 5 A's of smoking cessation interventions (Table 2). The most commonly self-reported interventions were the first three A's (Ask, Advise, Assess) with only $42.8 \%$ of respondents providing all 5 A's. 
Citation: Cantin C, Peterson WE, Davies B, Woodend K (2014) Opportunities to Improve the Role of Family Practice Nurses in Increasing the Uptake of Evidence-Based Smoking Cessation Interventions for Pregnant Women: An Exploratory Survey. Primary Health Care 4: 174. doi:10.4172/2167-1079.1000174

Page 4 of 8

\begin{tabular}{|c|c|c|}
\hline & & $\mathrm{n}(\%)$ \\
\hline \multirow[t]{5}{*}{ Age $(N=60)$} & $20-29$ & $6(10)$ \\
\hline & $30-39$ & $8(13.3)$ \\
\hline & $40-49$ & $14(23.3)$ \\
\hline & $50-59$ & $26(43.3)$ \\
\hline & $>60$ & $6(10)$ \\
\hline \multirow[t]{4}{*}{ Place of Work $(\mathrm{N}=63)$} & Family Health Team & $28(43.8)$ \\
\hline & Community Health Centre & $4(6.3)$ \\
\hline & Physician's Office & $25(39.1)$ \\
\hline & Other* & $6(9.4)$ \\
\hline \multirow[t]{3}{*}{ Highest Nursing Education ( $\mathrm{N}=63$ ) } & Bachelor's Degree & $16(25)$ \\
\hline & Diploma & $45(70.3)$ \\
\hline & Master's degree & $2(3.1)$ \\
\hline \multirow[t]{3}{*}{ Professional license $(\mathrm{N}=64)$} & Registered Nurse & $58(90.6)$ \\
\hline & Registered Practical Nurse & $4(6.3)$ \\
\hline & Nurse Practitioner & $2(3.1)$ \\
\hline \multirow[t]{5}{*}{ Years in Current Position $(\mathrm{N}=64)$} & Less than 2 years & $11(17.2)$ \\
\hline & $2-5$ years & $26(40.6)$ \\
\hline & $6-10$ years & $10(15.6)$ \\
\hline & $11-15$ years & $4(6.3)$ \\
\hline & More than 16 years & $13(20.3)$ \\
\hline \multirow[t]{3}{*}{ Employment Status $(\mathrm{N}=64)$} & Full time & $41(64.1)$ \\
\hline & Part time & $20(31.3)$ \\
\hline & Casual & $3(4.7)$ \\
\hline \multirow[t]{2}{*}{ SC Training DURING Nursing studies $(\mathrm{N}=62)$} & Yes & $8(12.9)$ \\
\hline & No & $54(87.1)$ \\
\hline \multirow[t]{2}{*}{ SC Training AFTER Nursing studies $(\mathrm{N}=62)$} & Yes & $24(38.7)$ \\
\hline & No & $38(61.3)$ \\
\hline \multirow[t]{4}{*}{ Smoking Status $(\mathrm{N}=64)$} & Always been a non-smoker & $41(64.1)$ \\
\hline & An ex-smoker & $22(34.4)$ \\
\hline & Occasional smoker & $1(1.6)$ \\
\hline & Daily smoker & 0 \\
\hline \multirow{4}{*}{$\begin{array}{l}\text { Size of Community } \\
(\mathrm{N}=64)\end{array}$} & Rural & $21(32.8)$ \\
\hline & Small city $<100,000$ & $14(21.9)$ \\
\hline & Medium city $100-500,000$ & $15(23.4)$ \\
\hline & Large city $>500,000$ & $14(21.9)$ \\
\hline
\end{tabular}

Table 1: Family Practice Nurses’ demographics, smoking status and smoking cessation training 
Citation: Cantin C, Peterson WE, Davies B, Woodend K (2014) Opportunities to Improve the Role of Family Practice Nurses in Increasing the Uptake of Evidence-Based Smoking Cessation Interventions for Pregnant Women: An Exploratory Survey. Primary Health Care 4: 174. doi:10.4172/2167-1079.1000174

Page 5 of 8

\begin{tabular}{|l|l|}
\hline Smoking cessation intervention & $\begin{array}{l}\text { Nurses who routinely provide SC } \\
\text { intervention to half or more of their } \\
\text { pregnant clients } \\
\mathrm{n}(\%)\end{array}$ \\
\hline Ask/Document smoking status & $51 / 63(81.0)$ \\
\hline Advise client to quit smoking & $44 / 62(71.0)$ \\
\hline Assess readiness to quit smoking & $44 / 62(71.0)$ \\
\hline Assist* & $33 / 59(56.0)$ \\
\hline Arrange follow-up appointment & $30 / 58(51.7)$ \\
\hline $\begin{array}{l}\text { * Refer the client to community resources, self-help materials, other health care } \\
\text { professionals, or smoker's helpline }\end{array}$ \\
\hline
\end{tabular}

Table 2: Proportion of Family Practice Nurses who provided the 5 A's of smoking cessation interventions to pregnant clients who smoke

\section{Awareness and Use of Smoking Cessation Guidelines}

Approximately half of the respondents (53\%) were able to identify the guideline in use at their place of work. The most frequently reported guidelines being used by FPNs were the RNAO BPG "Integrating Smoking Cessation Intervention into Daily Nursing Practice" (44\%) and the Ottawa Model for Smoking Cessation (36\%). Thirty-seven percent of respondents reported that they did not use a particular guideline at their place of work while $10 \%$ of respondents did not know which guideline they use at their place of work.

Over half of respondents (58\%) identified that they were aware of the RNAO BPG. Of the 37 respondents who were aware of this BPG, the majority of respondents $(81 \%)$ identified that they had read the document. Of the respondents who had read the RNAO BPG, the results were mixed in terms of usefulness of the BPG to change practice; $48 \%$ identified that it helped to change their SC practice a "whole lot" or "quite a lot".

Participant self-reported practices were compared to the minimal and intensive smoking cessation interventions, as per the RNAO BPG Practice Recommendations. Fourteen percent of respondents reported that they never offer smoking cessation counselling to pregnant women. Twenty-seven percent of respondents identified that they spend one to three minutes (minimal intervention), during a prenatal visit, counselling pregnant women who smoke. Approximately half of the respondents (52\%) reported that they spend between three to ten minutes. Six percent of respondents spend 10 or more minutes counselling (intensive intervention) as per the recommendations by RNAO for pregnant women.

\section{Factors Associated with FPNs' Smoking Cessation Counselling for Pregnant Women}

Data analysis was completed in order to determine which factors predicted FPNs' smoking cessation counselling for pregnant women who were "ready to quit" and "not ready to quit". None of the six independent variables were correlated $>.80$ and therefore, there was no evidence of multicollinearity. Finally, internal consistency was tested. The Cronbach's alpha for the "beliefs" and "self-efficacy" scales were 76 and .89 respectively indicating that they were reliable measures.

\section{Counselling women who are "ready to quit"}

The mean counselling score for pregnant women who are "ready to quit" was 29.3 [ $S D=13.4$ ] (range of scores was 10 - 48, with higher scores indicating FPNs provided more SC counselling). Simple linear regressions were completed for the dependent variable "ready to quit" and each of the six independent variables (Table 3 ).

\begin{tabular}{|l|l|l|l|l|l|l|l|l|}
\hline & \multicolumn{3}{|l|}{ Ready to quit } & \multicolumn{3}{l|}{ Not ready to quit } \\
\hline & $\mathrm{n}$ & $\mathrm{B}$ & $\mathrm{t}$ & $\mathrm{p}$ & $\mathrm{N}$ & $\mathrm{B}$ & $\mathrm{t}$ & $\mathrm{p}$ \\
\hline Beliefs & 53 & .525 & 4.450 & $<.001^{*}$ & 54 & .514 & 4.360 & $<.001^{*}$ \\
\hline Self-efficacy & 54 & .678 & 6.709 & $<.001^{*}$ & 55 & .528 & 4.566 & $<.001^{*}$ \\
\hline Age & 50 & -.108 & -.763 & .449 & 51 & -.074 & -.528 & .600 \\
\hline $\begin{array}{l}\text { Interest in } \\
\text { updating SC } \\
\text { knowledge }\end{array}$ & 54 & .110 & .804 & .425 & 55 & -.053 & -.388 & .700 \\
\hline $\begin{array}{l}\text { SC training } \\
\text { during } \\
\text { nursing } \\
\text { school }\end{array}$ & 54 & .167 & 1.231 & .224 & 55 & .115 & .854 & .397 \\
\hline $\begin{array}{l}\text { SC training } \\
\text { after nursing } \\
\text { school }\end{array}$ & 52 & .386 & 2.986 & $.004^{*}$ & 53 & .324 & 2.466 & $.017^{*}$ \\
\hline * significant predictor & & & & & & & & \\
\hline
\end{tabular}

Table 3: Simple linear regression: SC counselling for pregnant women

Independent variables for which the simple linear regression coefficients were $\mathrm{p}<.20$ included beliefs $(\mathrm{p}<.001)$, self-efficacy $(\mathrm{p}<.001)$, and SC training after nursing school $(\mathrm{p}=.004)$ [24]. These three variables were therefore included as independent variables in the multiple linear regression analysis predicting SC counselling for women who are "ready to quit". Overall, the regression was significant $\left[\mathrm{F}(3,51)=19.284, \mathrm{p}<.001, \mathrm{R}^{2}=.547\right]$. Of the three predictors investigated, only self-efficacy $(\mathrm{p}<.001)$ was a significant predictor of SC counselling of women who are "ready to quit" (see Table 4).

\section{Counselling women who are "not ready to quit"}

The mean counselling score for pregnant women who are "not ready to quit" was $30.6[\mathrm{SD}=13.4]$ (range was from the minimum 9 to maximum 45 score possible), with higher scores indicating FPNs provided more SC counselling to pregnant women who were "not ready to quit" smoking. Simple linear regressions were completed for the dependent variable "not ready to quit" and each of the six independent variables (Table 3). Independent variables that had a regression coefficient for which $\mathrm{p}<.20$ included beliefs $(\mathrm{p}<.001)$, self- 
Citation: Cantin C, Peterson WE, Davies B, Woodend K (2014) Opportunities to Improve the Role of Family Practice Nurses in Increasing the Uptake of Evidence-Based Smoking Cessation Interventions for Pregnant Women: An Exploratory Survey. Primary Health Care 4: 174. doi:10.4172/2167-1079.1000174

Page 6 of 8

efficacy $(\mathrm{p}<.001)$, and SC training received after nursing school $(\mathrm{p}=$ 017). These three variables were therefore included as independent variables in the multiple linear regression analysis predicting SC counselling for women who are "not ready to quit".

Overall, the regression was significant $\left[F(3,52)=10.108, \mathrm{p}<.001, \mathrm{R}^{2}=\right.$. $382]$. Of the predictors investigated, only self-efficacy $(\mathrm{p}=.018)$ was a significant predictor of SC counselling of women who are "not ready to quit" (see Table 4).

\begin{tabular}{|l|l|l|l|l|l|l|}
\hline & \multicolumn{3}{|l|}{ Ready to quit } & \multicolumn{3}{l|}{ Not ready to quit } \\
\hline & $\mathrm{B}$ & $\mathrm{t}$ & $\mathrm{p}$ & $\mathrm{B}$ & $\mathrm{t}$ & $\mathrm{p}$ \\
\hline Beliefs & .144 & 1.149 & .256 & .287 & 1.979 & .053 \\
\hline Self-efficacy & .585 & 4.545 & $<.001^{*}$ & .366 & 2.443 & $.018^{*}$ \\
\hline $\begin{array}{l}\text { SC training } \\
\text { after nursing } \\
\text { school }\end{array}$ & .113 & 1.041 & .303 & .061 & .478 & .635 \\
\hline
\end{tabular}

Ready to quit: $\operatorname{df}(3,51) \mathrm{F}=19.284, \mathrm{p}<.001, \mathrm{R}^{2}=.547$, adj $\mathrm{R}^{2}=.518$

Not ready to quit: $\mathrm{df}(3,52) \mathrm{F}=10.108, \mathrm{p}<.001, \mathrm{R}^{2}=.382, \operatorname{adj} \mathrm{R}^{2}=.344$

* significant predictor

Table 4: Multiple linear regression results for SC counselling for pregnant women

\section{Barriers to Smoking Cessation Interventions}

The three most frequently identified significant or highly significant barriers to providing SC interventions for pregnant women included the following: cost of medication (55\%), lack of time (52\%), and lack of knowledge about smoking cessation (33\%).

\section{Discussion}

This study describes FPNs' SC counselling practices for pregnant women who are seeking routine prenatal care at primary care settings in Ontario, Canada. The results of this exploratory study support our hypothesis that the RNAO BPG guideline was the most frequently reported SC guideline used by FPNs. However, the majority of FPNs in this study are not providing the intensive intervention recommended for pregnant women. Furthermore, FPNs are not consistently implementing all aspects of the 5 A's of smoking cessation guidelines. Respondents identified that for half or more of the pregnant women they see, during routine prenatal care visits, 56\% "Assist" with the quitting process and 52\% "Arrange" follow-up support. This finding is consistent with other studies exploring health care providers' counselling practices for pregnant smokers in Canada and the United States $[18,26,27]$. Despite having evidence-based best practice guidelines for smoking cessation for more than a decade, the rate of guideline implementation is sub-optimal. It is likely that additional organizational and professional support is required to help FPNs achieve optimal cessation counselling practices.

FPNs have an important role in the provision of perinatal care given that the majority of respondents $(70 \%)$ reported that they see one to five pregnant women per day, with a further $12 \%$ of respondents who see more than five pregnant women per day. FPNs are optimally situated within the Canadian health care system to provide smoking cessation counselling; however, they are often overlooked in studies or reports about the collaborative maternity care team. All health care providers need to work to their full scope of practice to maximize health care funding dollars and optimize patient outcomes. Physicians, midwives, nurses and other health care professionals need to be held accountable for their respective roles and responsibilities in providing interventions to pregnant women who smoke. FPNs must advocate for their role in providing smoking cessation interventions and they must be supported by their nursing and interprofessional colleagues to improve their efforts to provide SC interventions for pregnant women because a "strong dose-response relationship exists between intensity of tobacco dependence counselling and effectiveness" (p. 202) [28]. FPNs need to implement the full range of smoking cessation interventions, as appropriate, for each woman. However, the appropriate interventions would be different depending on whether or not the woman is ready to quit smoking.

In this study, FPNs' self-efficacy predicted the frequency and quality of their SC counselling for pregnant women who were "ready to quit" and for pregnant women who are "not ready to quit". FPNs that had a higher self-perceived ability to provide effective SC counselling were more likely to provide SC counselling. In contrast to our findings, Tremblay et al. found that nurses' self-efficacy and beliefs were significantly associated with SC counselling of women who were "ready to quit", and that only beliefs were significantly associated with the "not ready to quit" counselling score for nurses. Further exploration of FPNs' beliefs with a larger sample of FPNs would yield greater information regarding the extent to which beliefs influence counselling interventions for pregnant women.

Bandura defines perceived self-efficacy as "belief in one's capabilities to organize and execute the courses of action required to produce given attainments" (p.3) [29]. According to Bandura's Social Cognitive Theory of self-efficacy [29], it may be that FPNs who have higher levels of self-efficacy for smoking cessation counselling are more likely to put greater effort into counselling pregnant women, are more likely to persevere despite obstacles or failures, and are more likely to achieve the level of accomplishment that they set forth to attain. It is possible that FPNs may lack the ability to adequately address social realities, suggest appropriate strategies to overcome barriers, and their work environments may lack the structure to monitor women's progress towards SC goals [29]. Although SC training was not a significant predictor of counselling practices in the current study, researchers have suggested that health care providers' self-efficacy to provide effective counselling can be enhanced through additional education $[19,26,27]$. In the current study, only $39 \%$ of respondents had received training in smoking cessation interventions after their nursing studies and one third (33\%) of participants identified lack of knowledge regarding SC as a significant to highly significant barrier to providing SC interventions for pregnant women.

In the current study, the two most frequently self-reported "significant" or "highly significant" barriers to providing SC interventions for pregnant women were cost of medication (55\%) and lack of time $(52 \%)$. In a literature review of quantitative studies pertaining to health care providers' engagement in smoking cessation with pregnant smokers, lack of time was identified as the most frequently reported systemic/organizational barrier [18]. Similarly, in a study exploring US midwives' knowledge, perception, beliefs and practice support regarding tobacco dependence treatment for pregnant women, the authors reported that cost of medication $(63.4 \%)$ and lack of time $(48.8 \%)$ were common barriers to counselling pregnant women [26]. Abatemarco et al. identified other barriers to the provision of SC interventions for pregnant women: patients are 
resistant to advice (81.1\%), patients lacked interest (78.1\%), competing priorities in the visit such as acute illness $(72.9 \%)$ and lack of training or experience in smoking cessation (72.8\%). Price et al. surveyed 93 midwives in Ohio regarding their perception and use of smoking cessation in nurse-midwives practice; midwives in this study reported minimal to no barriers to providing SC counselling for pregnant women [27]. The majority of respondents perceived there were no barriers to counselling pregnant women and only $14 \%$ of midwives in this study identified lack of time as a barrier.

Interventions to reduce the barriers to FPN-provided SC should be implemented. A surprising finding was that cost of medication was the most frequently identified barrier given that there a number of programs in the province that provide smoking cessation medications or nicotine replacement therapies at a reduced cost or for free. For example, residents of the province who are eligible to receive Ontario Drug Benefits will receive free smoking cessation medications if needed. Additionally, there are programs offered through public health units in the province specifically developed for pregnant women whereby nicotine replacement therapy is provided as appropriate. Information regarding available programs to provide smoking cessation support for pregnant women should be widely promoted.

A simple intervention would be to refer women to the Smokers' Helpline via faxed referral, or to encourage women to self-refer via the website http://smokershelpline.ca/ or phone number 1-877-513-5333. The Smokers' Helpline is a federally funded program (Health Canada) which provides support to residents in 7 provinces including Ontario. The helpline would be able to connect women to local resources or provide direct quit coaching via phone, online support or text messaging. Referral to a smoking cessation program or service would also help to minimize the perceived time barrier and lack of SC knowledge reported by participants. By assisting women in this way, FPNs will be fulfilling clinical practice guideline recommendations, assuming they follow-up to ensure that the resource has been helpful to the women.

Further research is required to identify effective strategies to increase FPNs' knowledge regarding SC. Tong et al. conducted a national survey of US health professionals' smoking prevalence, cessation practices and beliefs [30]. Tong et al. reported that having training in SC was positively associated with performing multiple components of the $5 \mathrm{~A}$ 's of the smoking cessation guidelines (Ask, Advise, Assess, Assist, Arrange) [30]. There is evidence that student nurses do not receive adequate education in SC and consequently nurses do not feel prepared to perform this aspect of the nursing role $[19,31]$. Given that in this study there was a threefold increase in SC training after nursing studies, it would appear that FPNs are interested in enhancing their knowledge. Some FPNs work in isolation from peers and may have limited access to continuing education opportunities [32]. Internet-based education may be a cost effective and convenient way for FPNs to acquire additional knowledge [33]. A variety of resources including on-line modules can be found on the Tobacco Free RNAO website [34]. Additionally, the Centre for Addiction and Mental Health host a website entitled "Prevention of Gestational and Neonatal Exposure to Tobacco Smoke" (Pregnets) which provides extensive information pertaining to pregnant and postpartum women [35].

This study is limited by a low response rate and a lack of generalizability of findings. The findings must be interpreted with caution. A similar study regarding smoking cessation practices among primary care providers in Ontario was conducted at the same time and response fatigue may have contributed to a low response rate. An internet-based recruitment method versus mailed questionnaires was used because e-mail is the primary mode of communication with these members of the FPNs' interest group and mailing addresses were not available. The nurses who completed the questionnaire were members of a voluntary professional association and may not be representative of the FPN population in Ontario. A larger and more representative sample size with predefined mailing lists is needed to more confidently draw conclusions regarding the nurses' role in providing smoking cessation for pregnant women. Additionally, a minority of respondents received training in SC which may have lessened the statistical power to assess the impact of training on SC counselling practices. Future studies should recruit FPNs through regulatory colleges which have mailing addresses available and defined processes for research involving their members. In the future, researchers should consider a combined recruitment method of mailed and internet surveys with careful attention to the timing of the questionnaire distribution.

The strengths of this study were the utilization of a previously validated instrument and the exploration of nurses' SC counselling for pregnant women who were not ready to quit smoking. Although minor adaptations were made to the instrument to ensure relevancy for pregnant women, the reliability and content validity remained high.

\section{Conclusion}

Eighty-two percent of Family Practice Nurses surveyed in this study reported seeing pregnant women on a daily basis in their primary care practices. The results from this exploratory survey indicate that the majority of FPNs in this study are not fully implementing evidencebased smoking cessation interventions during routine care. Of the predictors investigated, self-efficacy was a significant predictor of counselling pregnant women who were "ready to quit" $(\mathrm{p}<.001)$ and "not ready to quit" $(\mathrm{p}=.018)$. FPNs that have high self-efficacy to provide effective smoking cessation counselling are more likely to provide interventions.

Disseminating research outlining effective strategies to increase nurses' self-efficacy to provide effective smoking cessation interventions may increase the uptake of evidence-based recommendations. Interventions to address the barriers to FPNprovided SC should be implemented. Greater promotion of community programs is recommended. As FPNs become more familiar with smoking cessation programs for pregnant women then perhaps referrals to these programs will increase thereby decreasing the perceived barrier of time and cost of medication. Family practice nurses can empower, motivate, and support pregnant women who smoke so that SC efforts started during pregnancy will not stop with the birth of the child but rather continue towards life-long abstinence. Now is the time to make the 5 A's of smoking cessation counselling routine practice for all nurses working in all settings, especially FPNs who work with pregnant and postpartum women.

\section{Acknowledgement}

The authors gratefully acknowledge the following individuals: Dr. Michèle Tremblay who provided permission to modify and use the questionnaire; Juddie Surridge and Barb Thompson of the Ontario Family Practice Nurses' (OFPN) interest group of the Registered 
Citation: Cantin C, Peterson WE, Davies B, Woodend K (2014) Opportunities to Improve the Role of Family Practice Nurses in Increasing the Uptake of Evidence-Based Smoking Cessation Interventions for Pregnant Women: An Exploratory Survey. Primary Health Care 4: 174. doi:10.4172/2167-1079.1000174

Page 8 of 8

Nurses' Association of Ontario who helped to recruit participants for this study; members of the OFPN for participating in this study; and members of the Nursing Best Practice Research Centre.

CC gratefully acknowledges the financial support received from: the Registered Nurses' Foundation of Ontario, Maternal Child Nurses' Interest Group Scholarship; The Ottawa Hospital, Nursing Professional Practice Department; and the University of Ottawa, Faculty of Graduate and Postdoctoral Studies.

\section{References}

1. Centers for Disease Control and Prevention Website: Reproductive health: Tobacco use and pregnancy.

2. Chalmers B, Dzakpasu S, Heaman M, Kaczorowski J (2008) The Canadian maternity experiences survey: an overview of findings. J ObstetGynaecol Can 30: 217-228.

3. Flenady V, Macphail J, New K, Devenish-Meares P, Smith J (2008) Implementation of a clinical practice guideline for smoking cessation in a public antenatal care setting. Aust N Z J ObstetGynaecol 48: 552-558.

4. Health Canada: Pregnancy: Smoking and your body.

5. Reinold C, Dalenius K, Brindley P, Smith B, Grummer-Strawn L (2011) Pregnancy nutrition surveillance 2009 report. Atlanta- Georgia: U.S Department of Health and Human Services, Centers for Disease Control and Prevention.

6. Greaves L, Horne T, Poole N, Jategaonkar N, McCullough L: Quit smoking telephone counselling protocol for pregnant and postpartum women.

7. Pregnets: Smoking cessation for pregnant and post-partum women: A toolkit for health professionals.

8. Selby P, Dragonetti R (2007) Pragmatic strategies to help pregnant smokers quit. Smoking Cessation Rounds 1: 1-6.

9. Association of Women's Health, Obstetric and Neonatal Nurses (2012) Position statement: Smoking and women's health. Nursing for Women's Health 14: 427-429.

10. Chalmers K, Gupton A, Katz A, Hack T, Hildes-Ripstein E, et al.(2004) The description and evaluation of a longitudinal pilot study of a smoking relapse/ reduction intervention for perinatal women. J AdvNurs 45: 162-171.

11. Fiore MC, Jaén CR, Baker TB, Bailey WC, Benowitz N, et al.(2008) Treating tobacco use and dependence.

12. Registered Nurses' Association of Ontario (2007) Integrating smoking cessation into daily nursing practice (revised). Toronto, Ontario: Registered Nurses' Association of Ontario.

13. Canadian Action Network for the Advancement, Dissemination and Adoption of Practice-informed Tobacco Treatment: Pregnant and breastfeeding women.

14. Lumley J, Chamberlain C, Dowswell T, Oliver S, Oakley L, et al. (2009) Interventions for promoting smoking cessation during pregnancy. Cochrane Database of Syst Rev, 3.

15. Scalera A, Koren G (1998) Rationale for treating pregnant smokers with nicotine patches. Can Fam Physician 44: 1601-1603.
16. Campbell R, Murphy DJ (2009) Smoking in pregnancy. BMJ 338: b2188.

17. Filion KB, Abenhaim HA, Mottillo S, Joseph L, Gervais A, et al. (2011) The effect of smoking cessation counselling in pregnant women: a metaanalysis of randomised controlled trials. BJOG 118: 1422-1428.

18. Okoli CT, Greaves L, Bottorff JL, Marcellus LM (2010) Health care providers' engagement in smoking cessation with pregnant smokers. J ObstetGynecol Neonatal Nurs 39: 64-77.

19. Tremblay M, Cournoyer D, O'Loughlin J (2009) Do the correlates of smoking cessation counseling differ across health professional groups? Nicotine Tob Res 11: 1330-1338.

20. White DE, Fraser-Lee NJ, Tough S, Newburn-Cook CV (2006) The content of prenatal care and its relationship to preterm birth in Alberta, Canada. Health Care Women Int 27: 777-792.

21. Health Force Ontario: Health care in Ontario (2007). Primary health care.

22. Registered Nurses' Association of Ontario (2012) Primary solutions for primary care: Maximizing and expanding the role of the primary care nurse in Ontario. Toronto, Ontario: Registered Nurses' Association of Ontario.

23. Tremblay M, Cournoyer D, Jukic D, O'Loughlin J (2007) Smoking cessation counselling: Results of a 2005 survey of Quebec nurses. Montreal, Quebec: Institut National de Santé Publique.

24. Katz MH (1999) Multivariable analysis: A practical guide for clinicians. New York, New York: Cambridge University Press.

25. Dillman DA, Smyth JD, Christian LM (2009) Internet, mail and mixedmode surveys: The tailored design method. Hoboken, New Jersey: John Wiley \& Sons, Inc.

26. Abatemarco DJ, Steinberg MB, Delnevo CD (2007) Midwives' knowledge, perceptions, beliefs, and practice supports regarding tobacco dependence treatment. J Midwifery Womens Health 52: 451-457.

27. Price JH, Jordan TR, Dake JA (2006) Perceptions and use of smoking cessation in nurse-midwives' practice. J Midwifery Womens Health 51: 208-215.

28. Murray E, Wewers ME (2004) Nurses can play a significant role in reducing tobacco use in the U.S. AWHONN Lifelines 8: 200-202, 205-6.

29. Bandura A (1977) Self-efficacy: The exercise of control. New York, New York: W.H. Freeman and Company.

30. Tong EK, Strouse R, Hall J, Kovac M, Schroeder SA (2010) National survey of U.S. health professionals' smoking prevalence, cessation practices, and beliefs. Nicotine Tob Res 12: 724-733.

31. Lenz BK (2008) Beliefs, knowledge, and self-efficacy of nursing students regarding tobacco cessation. Am J Prev Med 35: S494-500.

32. Alsaffar A: Family practice: A nursing perspective.

33. Carpenter KM, Carlini BH, Painter I, Mikko AT, Stoner SA (2012) Refer2Quit: impact of Web-based skills training on tobacco interventions and quitline referrals. J ContinEduc Health Prof 32: 187-195.

34. Registered Nurses' Association of Ontario: New smoking cessation elearn courses.

35. Centre for Addiction and Mental Health: Prevention of gestational and neonatal exposure to tobacco smoke. 